\title{
Risk Stratification and Early Conservative Treatment of Acute Pancreatitis
}

\author{
Michał Żorniak $^{\mathrm{a}}$ Georg Beyer $^{\mathrm{b}} \quad$ Julia Mayerle ${ }^{\mathrm{b}}$ \\ ${ }^{a}$ Department of Gastroenterology, Medical University of Silesia, Katowice, Poland; b Department of Medicine II, \\ University Hospital, LMU Munich, Munich, Germany
}

Keywords

Systemic inflammatory response syndrome $\cdot$ Bedside Index of Severity in Acute Pancreatitis - Goal-directed fluid resuscitation · Pain management · Prophylactic antibiotics

\section{Abstract}

Background: Acute pancreatitis (AP) is a potentially lifethreatening common gastrointestinal disorder with increasing incidence around the globe. Although the majority of cases will take an uneventful, mild course, a fraction of patients is at risk of moderately severe or severe pancreatitis which is burdened with substantial morbidity and mortality. Early identification of patients at risk of a severe disease course and an adopted treatment strategy are crucial to avoid adverse outcomes. Summary: In this review we summarize the most recent concepts of severity grading in patients diagnosed with AP by adopting recommendations of current guidelines and discussing them in the context of the available literature. The severity of AP depends on the presence of local and/or systemic complications and organ failure. To predict the severity early in the disease course, host-specific factors (age, comorbidities, body mass index), clinical risk factors (biochemical and physiological parameters and scoring systems), as well as the response to initial therapy need to be considered and revisited in the short term. Depending on the individual risk and comorbidity the initial treatment can be guided, which will be discussed in the second part of this review. Key Message: Predicting the severity of AP and adapting the individual treatment strategy requires multidimensional risk assessment and close observation during the early phase of AP development.

(c) 2019 S. Karger AG, Basel

\section{Introduction}

Acute pancreatitis (AP) is a potentially life-threating disease with a broad spectrum of possible clinical courses and manifestations. Various etiologies have been described; however, gallstones and alcohol abuse are responsible for up to $80 \%$ of cases, with regional differences in frequency [1]. Although there is often no specific therapy for the underlying cause, the etiology of AP should be identified early in the disease course.

AP is the leading cause of hospital admissions among benign gastrointestinal conditions, with more than 275,000 annual hospitalizations in the United States. The incidence varies from 5 to 30 cases per 100,000 individuals [2]. There is evidence for an increase in the incidence of AP over the last decade, but these data need to be interpreted with caution, since acute bouts of chronic pancreatitis are often counted as AP in registries and insurance records [3].

The diagnosis of AP is based on the fulfillment of two out of three of the following criteria: clinical (characteristic upper abdominal pain), biochemical (serum amylase or lipase $>3$ times the upper limit of normal), and/or typical findings on imaging (computed tomography, magnetic resonance imaging, ultrasonography) [4]. It is worth mentioning that in most scenarios imaging is not required to diagnose AP (except for situations such as unconscious patients, suspicion of perforation or vascular disease, etc.).

Mortality and AP-associated morbidity depend on disease severity. According to the revised Atlanta Classification [4] the severity of AP can be categorized as mild,

\section{KARGER}

(C) 2019 S. Karger AG, Basel

E-Mail karger@karger.com www.karger.com/vis
Julia Mayerle, MD

Department of Medicine II, University Hospital, LMU Munich

Marchioninistrasse 15

DE-81773 München (Germany)

E-Mail julia.mayerle@med.uni-muenchen.de 
moderately severe, and severe (for details see below). The overall mortality of AP is $<5 \%$, but it can be as high as $50 \%$ in patients with severe AP or infected necrosis $[5,6]$. Interestingly, novel retrospective data on a large cohort of patients with infected pancreatic necrosis indicate that mortality does not correlate with onset (early versus late) and duration of organ failure, nor does the combination of infected pancreatic necrosis with organ failure result in higher mortality [7].

Early prediction of AP severity is crucial to guide early treatment, choose the optimal level of care, and identify patients who might benefit from transfer to a specialized center. There are multiple scoring systems and biomarkers available which could aid in the prediction of AP severity. In the last decades there has been slow but essential progress in the treatment of AP, resulting in a change of long-held paradigms regarding initial management. In this review we briefly summarize the current knowledge on the risk stratification and early conservative treatment of AP.

\section{Pathophysiology and Classification of AP}

The pathophysiology of AP, especially the development of severe AP with multiorgan failure, is complex and not fully understood. Regardless of the underlying etiology, it is the inappropriate activation and release of pancreatic proteases followed by an overwhelming activation of inflammatory pathways within the pancreas that initiates AP and rapidly spreads to other organ systems in severe disease.

The development of AP is triggered by premature activation of trypsinogen to trypsin in response to a pathogenic stimulus or more rarely due to genetically determined auto-activation, overcoming the inherent protective mechanisms [8-10]. This results in activation of other proteases, subsequently leading to cell damage. The release of oxygen-derived free radicals, pro-inflammatory cytokines (e.g., IL-1, IL-6, IL-8, TNFa, PAF), cell damage-associated patterns (e.g., free mitochondrial DNA, rise in calcium concentration), and complement activation play a pivotal role in the transformation of AP from a local into a multiorgan inflammatory process often characterized by a systemic inflammatory response syndrome (SIRS) $[11,12]$. In response to pro-inflammatory cytokines, acute-phase reaction proteins are released and can be used to assess the severity of inflammation (e.g., C-reactive protein [CRP], IL-6, or procalcitonin [PCT]). Leukocyte migration and activation is probably also a key factor determining local and systemic complications [13$15]$.

It is not clear why only a relatively small group of patients will develop severe AP. Probably the strongest pre-
Table 1. Systemic inflammatory response syndrome criteria

$\begin{array}{ll}\text { Body temperature } & >38^{\circ} \mathrm{C} \text { or }<36^{\circ} \mathrm{C} \\ \text { Heart rate } & >90 / \mathrm{min} \\ \text { Respiratory rate } / \mathrm{paCO}_{2} & >20 \text { or }<32 \mathrm{~mm} \mathrm{Hg} \\ \text { White blood count } & >12,000 / \mathrm{mm}^{3} \text { or }<4,000 / \mathrm{mm}^{3}\end{array}$

dictor of adverse outcomes are preexisting comorbidities such as congestive heart failure, pulmonary or renal disease, and obesity. In addition, age has shown to negatively correlate with outcome [16-18]. It has also been suggested that genetic factors play a pivotal role in the clinical course of AP. One of the most disputed factors is the IL- 8 polymorphism. IL-8 is a chemoattractant cytokine which is synthesized by a variety of tissue and blood cells and attracts and activates neutrophils in inflammatory regions [19]. It has been demonstrated that patients with AP suffering from complications have elevated IL- 8 serum levels [20]. IL-8 A-allele (IL-8 - 251T/A) polymorphism is associated with increased IL-8 production and a higher risk of AP $[21,22]$. A recent paper by Teich et al. [23] revealed that blood group B is also an independent risk factor for azathioprine-induced AP in patients with inflammatory bowel disease.

According to the revised Atlanta Classification, there are two overlapping phases of AP: early and late [4]. The early phase, which usually lasts for the first week, is followed by a second later phase, which can run a protracted course from weeks to months. During the early phase, the inflammatory factors and cytokines mentioned before are activated by sterile pancreatic inflammation, which manifests clinically as SIRS. SIRS is defined as the presence of two or more diagnostic criteria (Table 1). Prolonged SIRS is associated with organ failure, which can be transient (resolving within $\leq 48 \mathrm{~h}$ ) or persistent (persisting for $>48 \mathrm{~h}$ ) and affect multiple organs [24]. The late phase is characterized by local complications such as acute necrotic collections, which can mature to walled-off necrosis and often get superinfected. Other late complications include bleeding, portal or splenic vein thrombosis, gastrointestinal motility dysfunction, malnutrition, ascites, or decompensated diabetes. Based on the above, the revised Atlanta Classification defines three degrees of severity of AP [4]: (1) mild AP: absence of organ failure and absence of local or systemic complications; (2) moderately severe AP: presence of transient organ failure ( $\leq 48 \mathrm{~h}$ ) or local or systemic complications in the absence of persistent organ failure; (3) severe AP characterized by persistent organ failure $(>48 \mathrm{~h})$.

Due to the difficulty in predicting the severity of AP, all patients should be admitted to hospital at the point of diagnosis. Patients with a mild course can be managed on regular wards and will be ready for discharge after only a few days of symptomatic care. Patients with moderately 


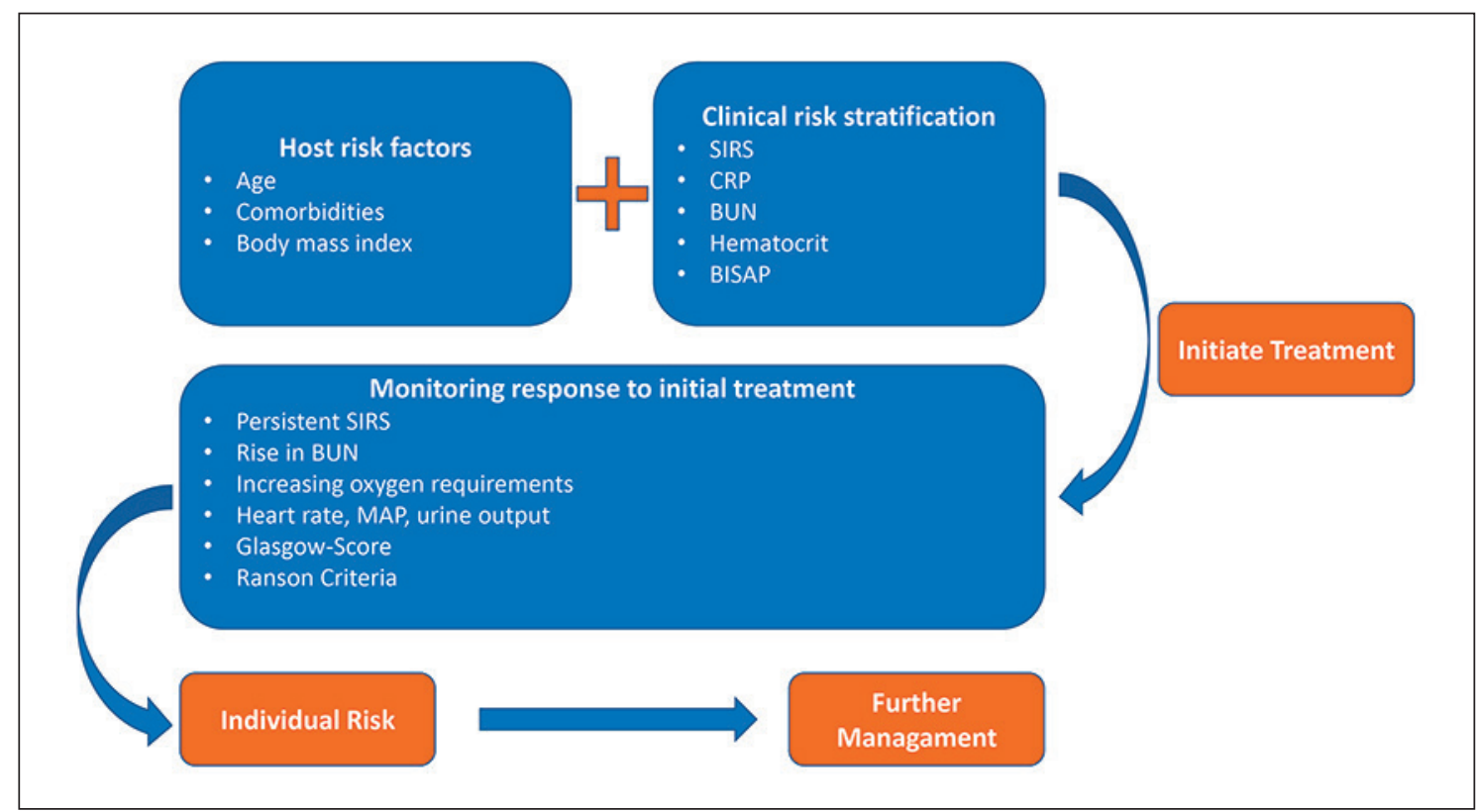

Fig. 1. Algorithm for the initial risk assessment in patients with AP based on host risk factors, clinical presentation on admission, and response to initial therapy. AP, acute pancreatitis; BISAP, Bedside Index of Severity in Acute Pancreatitis; BUN, blood urea nitrogen; CRP, C-reactive protein; SIRS, systemic inflammatory response syndrome.

severe or severe AP need to be observed more closely and care on a level 2 or 3 unit (intermediate or intensive care unit) might be necessary. The wide spectrum of possible clinical courses underlines the importance of risk stratification early in the course of AP and mandates close observation with short-term reevaluation.

There have been great efforts to find reliable tools for the prediction of AP severity. We will discuss the available clinical and radiological scores and their inherent limitations.

\section{Risk Stratification in AP}

The most recent American Gastroenterological Association Institute Guideline on Initial Management of Acute Pancreatitis emphasizes that there is no published observational study or randomized controlled trial proving that the use of severity prediction tools has any impact on clinical outcomes [25]. Previous international guidelines have highlighted the crucial role of prediction in AP in order to identify patients at risk of an adverse outcome. However, it was also acknowledged that there are many different scoring systems as well as single serum markers, none of which is superior in predicting persistent organ failure [16]. Similarly important to choosing the right parameters is interpreting them in the context of the individual patient and reassessing them during the dynamic course of the disease. The IAP/APA evidence-based guidelines of 2013 for the management of AP recommended a three-dimensional approach during the initial phase (Fig. 1).

The most commonly used scoring systems and parameters are listed in Table 2.

\section{Acute Physiology and Chronic Health Evaluation II (APACHE II)}

APACHE II is a complex scoring system with a high accuracy and prediction rate of the course and severity of AP. A score of $\geq 8$ points is a predictor of severe AP (sensitivity $65-83 \%$, specificity $77-91 \%$, positive predictive value (PPV) $23-69 \%$, and negative predictive value (NPV) 86-99\%) [26, 27]. APACHE II is a widely used scoring system in the intensive care setting, but its complexity and incorporation of 15 different parameters makes using the score cumbersome, as many of the obtained parameters are not readily available outside the ICU.

\section{Ranson Criteria for Pancreatitis Mortality}

This historical scale was first introduced in 1974 and is still used in some centers [28]. The Ranson criteria include 11 parameters which are assessed at the time of admission (5 parameters) and $48 \mathrm{~h}$ later (6 parameters). The scale has a high sensitivity and specificity in predicting a severe course of pancreatitis (83.9 and 78\%, respectively); however, its main disadvantage is that it can be estimated no earlier than $48 \mathrm{~h}$ after admission and that it was originally developed for mortality of biliary pancreatitis only. 
Table 2. Clinical and biochemical tools useful for predicting mortality and complications in the early phase of AP

\section{Multivariate scores}

APACHE II score

Not displayed in detail

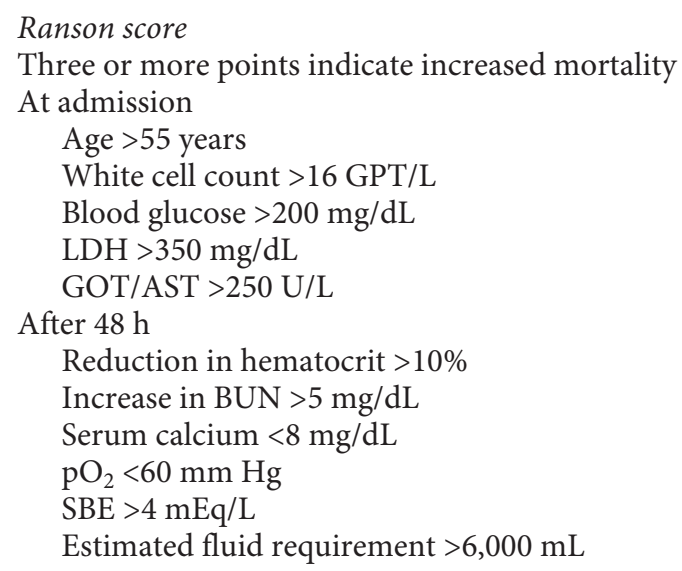

Glasgow Criteria (Glasgow-Imrie score)

Three or more points indicate increased mortality, estimation $48 \mathrm{~h}$ from admission Age $>55$ years

White cell count $>15 \mathrm{GPT} / \mathrm{L}$

$\mathrm{pO}_{2}<60 \mathrm{~mm} \mathrm{Hg}$

Blood glucose $>180 \mathrm{mg} / \mathrm{dL}(>10 \mathrm{mmol} / \mathrm{L})$

BUN under fluid resuscitation $>96 \mathrm{mg} / \mathrm{dL}(>6 \mathrm{mmol} / \mathrm{L})$

Serum calcium $<8 \mathrm{mg} / \mathrm{dL}(<2 \mathrm{mmol} / \mathrm{L})$

Albumin $<32 \mathrm{~g} / \mathrm{L}$

$\mathrm{LDH}>600 \mathrm{mg} / \mathrm{dL}$

Transaminases $>100 \mathrm{U} / \mathrm{L}$

BISAP

Score $>0$ at admission indicates increased risk of mortality

BUN $>25 \mathrm{mg} / \mathrm{dL}(>8.92 \mathrm{mmol} / \mathrm{L})$

Impaired mental status

$>2$ SIRS criteria

Age $>60$ years

Presence of pleural effusions

\section{Single parameters}

\section{Parameter \\ Age \\ Interpretation}

Age 55 years or older is associated with higher mortality

Body mass index

A body mass index $>25$ is associated with higher mortality

Hematocrit

Normal HCT (35-44\%) on admission and after $48 \mathrm{~h}$ is associated with low rate of complications and death CRP

Levels $>150 \mathrm{mg} / \mathrm{L}$ within $72 \mathrm{~h}$ from admission indicate risk of sever AP

BUN

Elevated BUN at admission or increase within $48 \mathrm{~h}$ is associated with mortality

AP, acute pancreatitis; APACHE II, Acute Physiology and Chronic Health Evaluation II; BISAP, Bedside Index of Severity in Acute Pancreatitis; BUN, blood urea nitrogen; CRP, C-reactive protein; HCT, hematocrit; SIRS, systemic inflammatory response syndrome. 


\section{Glasgow-Imrie Score}

This score was first proposed for estimation of the severity of both alcoholic and biliary AP. It uses eight laboratory factors $48 \mathrm{~h}$ after admission $\left(\mathrm{PaO}_{2}\right.$, age, white blood cells count, calcium, urea, $\mathrm{LDH}$, albumin, glucose), and more than three positive criteria indicate severe AP [29]. The sensitivity for the assessment of severe AP for the Glasgow-Imrie score is $56-85 \%$ [30].

\section{Bedside Index of Severity in Acute Pancreatitis (BISAP)}

The BISAP is dedicated to predicting AP-related inhospital mortality at the time of admission. It includes five relatively easy to obtain parameters: blood urea nitrogen (BUN), mental status, SIRS, age, and presence of pleural effusion [31]. The BISAP has been shown to be as accurate as other scores (APACHE II, Ranson score, CT severity index) for predicting the severity of AP [32].

To overcome the drawbacks of complex multivariate scoring systems, a lot of research has been done evaluating single parameters to assess and predict the severity of AP.

C-Reactive Protein. CRP is considered the most useful single biochemical marker of severe AP [33]. It is widely recognized that a CRP concentration $>150 \mathrm{mg} / \mathrm{L}$ in the first $72 \mathrm{~h}$ after the onset of symptoms indicates a severe course of AP with high sensitivity, specificity, PPV, and NPV (86, 87, 75, and 93\%, respectively) [34-36]. Moreover, CRP is a parameter which is widely available and used. On the other hand, CRP is not specific for AP, and other causes of inflammation must be considered, especially when it comes to acute cholangitis and AP overlapping in gallstone disease [37]. Although CRP overall has a high specificity and sensitivity, its increase can be delayed, resulting in reduced predictive strength very early after the onset of symptoms [38]. Repeated measurements are recommended.

Hematocrit. Admission hematocrit also seems to be an interesting and simple parameter in risk stratification in patients with newly recognized AP [39]. There are several studies showing that elevated hematocrit $(>44 \%)$ has a high NPV (93\% on admission, 97\% $24 \mathrm{~h}$ after admission), but a poor PPV predicting severe course of AP, organ failure pancreatic necrosis, or death [39-41]. Due to its low cost, high availability, and ease of interpretation it is a useful tool to recognize patients with low risk of severe AP.

Procalcitonin. PCT is another single biochemical marker that has been intensively investigated as an indicator for severe AP. PCT, in comparison to CRP mentioned above, is a more rapid acute-phase factor that indicates state of infection and sepsis. There are some promising data showing a potential role of PCT in predicting severe course at an early stage of disease. A Finn- ish study by Kylänpää-Bäck et al. [42] showed that a PCT test had a sensitivity of $94 \%$ and a specificity of $73 \%$ for development of organ failure when estimated in the first $24 \mathrm{~h}$ after admission. A meta-analysis published in 2006 [43] indicated a high diagnostic value of PCT for differentiation between mild and severe AP, but a significant heterogeneity between individual studies was noticed. Furthermore, a drawback of PCT is that its levels are often affected by comorbidity such as renal failure or calcium homeostasis.

Blood Urea Nitrogen. The BUN level is part of several complex clinical scoring systems in AP. Interestingly, an elevated BUN level at admission and an increase in BUN during the initial $24 \mathrm{~h}$ of hospitalization are independent risk factors for mortality in AP [44, 45]. Wu et al. [45] stated that the accuracy of serial BUN measurement was equal to that of the much more complex APACHE II score. This again highlights the importance of serial testing and reassessment of current treatment during the early phase of AP.

\section{Early Conservative Treatment of AP}

As mentioned before, treatment in the early phase of AP aims to eliminate symptoms (pain, nausea) and to prevent the development of complications (organ failure due to systemic inflammation, infection, and/or pancreatic necrosis). Fluid replacement, nutritional support, and pain management are the cornerstones of the early conservative treatment of AP. Interventional treatment is rarely necessary in the early phase, except when biliary pancreatitis presents with concomitant cholangitis. In this situation endoscopic retrograde cholangiography with sphincterotomy is indicated to treat cholangitis, but not pancreatitis [46]. Another causative treatment would include lowering triglycerides (insulin or plasmapheresis) in hypertriglyceridemia-induced pancreatitis and lowering calcium levels if hypercalcemia, preferably via hemodialysis, is the most likely cause of AP. In the following section we will focus on general aspects of conservative AP treatment.

\section{Fluid Replacement}

Fluid resuscitation is a crucial element of the early conservative treatment of AP. However, the evidence basis for fluid therapy in AP is relatively weak. Patients with mild AP usually have lower levels of fluid sequestration and thus lower fluid resuscitation requirements than patients with moderate or severe AP [47]. This is mainly due to the higher occurrence of serious complications of severe AP such as formation of fluid collections, necrosis, or multiorgan failure. Vice versa it has been demonstrated in retrospective studies that patients receiving inade- 
quate fluid replacement therapy are at higher risk of developing complications such as pancreatic necrosis [48, 49].

The intensity of fluid resuscitation is a matter of discussion. Two studies published by Mao et al. [50, 51] compared more aggressive $(10-15 \mathrm{~mL} / \mathrm{kg} / \mathrm{h})$ versus a less aggressive $(5-10 \mathrm{~mL} / \mathrm{kg} / \mathrm{h})$ fluid strategies or rapid hemodilution (hematocrit $<35 \%$ within $48 \mathrm{~h}$ ) versus moderate hemodilution (hematocrit $>35 \%$ within $48 \mathrm{~h}$ ). They found a higher rate of complications and need for mechanical ventilation in patients receiving more aggressive (re)hydration. They also showed that the survival rate in the slow hemodilution group (84.7\%) was higher compared to the rapid hemodilution group (66\%). Also for other indications, it has been shown that overly rapid fluid therapy puts patients at risk of severe adverse events such as abdominal hypertension and abdominal compartment syndrome [52]. To overcome the dilemma of finding the right fluid amount, the idea of goal-directed fluid therapy has been introduced, aiming to switch from resuscitation rate to maintenance rate if predefined physiological or biochemical goals are reached. Unfortunately, this strategy showed no benefits, but also no harm in clinical trials when compared to moderate fluid resuscitation guided by clinical judgement $[53,54]$. This strategy obviously forces a clinician to closely monitor the patient's physiology, and this in itself might increase the quality of care provided and explains why randomized trials did not show a significant benefit.

Despite the poor level of evidence, current guidelines recommend the use of preset physiological and biochemical targets in combination with a moderate aggressive infusion rate of $5-10 \mathrm{~mL} / \mathrm{kg} / \mathrm{h}$, mainly to adequately address the patient's fluid needs, but minimizing the risk of fluid overload [16, 25]. Suggested targets are a heart rate $<120 \mathrm{bpm}$ under adequate analgesia and a mean arterial pressure of $65-85 \mathrm{~mm} \mathrm{Hg}$ with urine output of at least $0.5 \mathrm{~mL} / \mathrm{kg} / \mathrm{h}$ or a hematocrit of $35-44 \%$.

Although the number of studies is low, it has become increasingly clear in the last years that using balanced crystalloid solutions such as Ringer's lactate for fluid therapy has a favorable impact when compared to normal saline due to a decrease in CRP levels and incidence of SIRS. The mechanism behind this is not fully understood, but one could speculate that the anti-inflammatory properties of lactate and the lower risk of sodium overload and hyperchloremic acidosis play a role. An advantage of using balanced crystalloids over normal saline in critically ill patients has also been found in cohorts not limited to pancreatitis [53]. Due to some evidence on increased multiple organ failure, using hydroxyethyl starch for resuscitation in AP is not recommended [55].

\section{Nutritional Support}

Oral feeding plays a pivotal role in the early conservative treatment of AP. Data coming from randomized controlled trials demonstrated that early feeding significantly reduces the risk of necrosis in the course of $\mathrm{AP}$ and diminishes the rates of infected peripancreatic necrosis and multiple organ failure [25]. Most probably, early enteral nutrition protects the mucosal intestinal barrier and reduces the risk of bacterial translocation [56]. Early feeding was demonstrated to be successful using various types of diet (i.e., low-fat, normal-fat, soft, and solid) [57]. Some patients are intolerant towards early oral feeding (mainly due to pain and vomiting) and may require placement of an enteral tube for nutritional support. However, in patients at risk of severe AP, a randomized controlled trial did not show a clinical benefit of tube feeding within $24 \mathrm{~h}$ versus on-demand tube feeding if oral diet was not tolerated after $72 \mathrm{~h} \mathrm{[58].} \mathrm{There} \mathrm{is} \mathrm{strong} \mathrm{evidence} \mathrm{showing}$ that enteral nutrition is beneficial in comparison to total parenteral nutrition. Enteral nutrition reduces the rate of infected peripancreatic necrosis as well as single and multiple organ failure [25]. Superiority of a specific type of diet has never been demonstrated in a controlled prospective manner.

\section{Pain Management}

Severe pain occurs frequently in AP. Since several studies proved that opioid analgesics (particularly morphine) do not cause dysfunction of the sphincter of Oddi, the $\mathrm{WHO}$ analgesia ladder is a pragmatic approach to the treatment of pain in AP [16]. It is based on stepwise escalation of treatment from low-potent to highly potent nonsteroidal anti-inflammatory drugs alone or in combination with opioids. There is lack of agreement on which analgesics should be preferred in the treatment of patients with AP. In a recent study, Gülen et al. [59] compared the analgesic effectiveness of tramadol (a synthetic opioid), paracetamol, and dexketoprofen in AP, showing no significant differences between the treated groups. There were some suggestions about pethidine as a potent opioid analgesic of choice in severe pain related to AP. Blamey et al. [60] proved that buprenorphine has a similar, strong analgesic activity, but a lower potential to cause opioid dependency. Intestinal paralysis and ileus are a common problem in early AP, which can get aggravated when using high doses of opioids. In some patients, use of an epidural catheter for pain relief might be considered.

\section{No Place for Prophylactic Antibiotics in the Early} Treatment of AP

It should be emphasized that there is a general worldwide trend to overuse antibiotics, which generates unnecessary costs and increases the risk of development of an- 
tibiotic resistance among bacteria and intestinal dysbiosis [61]. The IAP/APA guidelines clearly state that there is no proven benefit from prophylactic antibiotic intervention nor gut decontamination in AP [16]. Also, the most recent recommendations published in 2018 by the AGA recommend against the use of prophylactic antibiotics [25]. Based on a technical review of ten randomized controlled studies, the authors stated that prophylactic antibiotics had no impact on the rate of organ failure or the length of hospital stay. Though this recommendation statement was formed specifically for patients with severe AP, it should be clarified that there is no role either for prophylactic antibiotics in patients with milder forms of AP. Currently there is no consensus on the start of antibiotic therapy in AP patients with no positive bacterial culture test.

\section{Statement of Ethics}

The authors have no ethical conflicts to disclose.

\section{Disclosure Statement}

The authors have no conflicts of interest to declare.

\section{Fundling Sources}

PePPP center of excellence MV ESF/14-BM-A55-0045/16; DFG-CRC 1321.-P14.; DFG BE6395/1-1, DFG-GRK 1947-A3.

\section{Author Contributions}

All authors contributed equally to the making of this paper.

\section{References}

1 Gullo L, Migliori M, Oláh A, Farkas G, Levy $\mathrm{P}$, Arvanitakis $\mathrm{C}$, et al. Acute pancreatitis in five European countries: etiology and mortality. Pancreas. 2002 Apr;24(3):223-7.

2 Peery AF, Crockett SD, Murphy CC, Lund JL, Dellon ES, Williams JL, et al. Burden and Cost of Gastrointestinal, Liver, and Pancreatic Diseases in the United States: Update 2018. Gastroenterology. 2019 Jan;156(1):254-272.e11.

3 Krishna SG, Kamboj AK, Hart PA, Hinton A, Conwell DL. The Changing Epidemiology of Acute Pancreatitis Hospitalizations: A Decade of Trends and the Impact of Chronic Pancreatitis. Pancreas. 2017 Apr;46(4):482-8.

4 Banks PA, Bollen TL, Dervenis C, Gooszen HG, Johnson CD, Sarr MG, et al. Classification of acute pancreatitis - 2012: revision of the Atlanta classification and definitions by international consensus. Gut. 2013 Jan;62(1): 102-11.

5 Pavlidis P, Crichton S, Lemmich Smith J, Morrison D, Atkinson S, Wyncoll D, et al. Improved outcome of severe acute pancreatitis in the intensive care unit. Crit Care Res Pract. 2013;2013:897107.

6 Phillip V, Steiner JM, Algül H. Early phase of acute pancreatitis: assessment and management. World J Gastrointest Pathophysiol. 2014 Aug;5(3):158-68.

7 Schepers NJ, Bakker OJ, Besselink MG, Ahmed Ali U, Bollen TL, Gooszen HG, et al.; Dutch Pancreatitis Study Group. Impact of characteristics of organ failure and infected necrosis on mortality in necrotising pancreatitis. Gut. 2018 Jun doi: 10.1136/gutjnl2017-314657 [Epub ahead of print].

8 Whitcomb DC. Clinical practice. Acute pancreatitis. N Engl J Med. 2006 May;354(20): 2142-50.

9 Forsmark CE, Vege SS, Wilcox CM. Acute Pancreatitis. N Engl J Med. 2016 Nov;375(20): 1972-81.

10 Mayerle J, Sendler M, Hegyi E, Beyer G, Lerch MM, Sahin-Tóth M. Genetics and pathophysiology of pancreatitis. Gastroenterology. 2019 Jan doi: 10.1053/j.gastro.2018.11.081 [Epub ahead of print].
11 Sakorafas GH, Tsiotou AG. Etiology and pathogenesis of acute pancreatitis: current concepts. J Clin Gastroenterol. 2000 Jun; 30(4):343-56.

12 Bettac L, Denk S, Seufferlein T, Huber-Lang M. Complement in Pancreatic Disease-Perpetrator or Savior? Front Immunol. 2017 Jan; $8: 15$.

13 Sendler M, Dummer A, Weiss FU, Krüger B, Wartmann T, Scharffetter-Kochanek K, et al. Tumour necrosis factor a secretion induces protease activation and acinar cell necrosis in acute experimental pancreatitis in mice. Gut. 2013 Mar;62(3):430-9.

14 Sendler M, Weiss FU, Golchert J, Homuth G, van den Brandt $\mathrm{C}$, Mahajan UM, et al. Cathepsin B-mediated activation of trypsinogen in endocytosing macrophages increases severity of pancreatitis in mice. Gastroenterology. 2018 Feb;154(3):704-18.e10.

15 Shah AP, Mourad MM, Bramhall SR. Acute pancreatitis: current perspectives on diagnosis and management. J Inflamm Res. 2018 Mar;11:77-85.

16 Working Group IAP/APA Acute Pancreatitis Guidelines. IAP/APA evidence-based guidelines for the management of acute pancreatitis. Pancreatology. 2013 Jul-Aug;13(4 Suppl 2):e1-15.

17 Sternby H, Bolado F, Canaval-Zuleta HJ, Marra-López C, Hernando-Alonso AI, DelVal-Antoñana A, et al. Determinants of severity in acute pancreatitis: a nationwide multicenter prospective cohort study. Ann Surg. 2018 Apr doi: 10.1097/SLA. 0000000000002766 [Epub ahead of print].

18 Moran RA, García-Rayado G, de la IglesiaGarcía D, Martínez-Moneo E, Fort-Martorell E, Lauret-Braña E, et al. Influence of age, body mass index and comorbidity on major outcomes in acute pancreatitis, a prospective nation-wide multicentre study. United European Gastroenterol J. 2018 Dec;6(10):1508-18.
19 Hammond ME, Lapointe GR, Feucht PH, Hilt S, Gallegos CA, Gordon CA, et al. IL-8 induces neutrophil chemotaxis predominantly via type I IL-8 receptors. J Immunol. 1995 Aug; 155(3):1428-33.

20 Gross V, Andreesen R, Leser HG, Ceska M, Liehl E, Lausen $M$, et al. Interleukin-8 and neutrophil activation in acute pancreatitis. Eur J Clin Invest. 1992 Mar;22(3):200-3.

21 Yin YW, Sun QQ, Feng JQ, Hu AM, Liu HL, Wang Q. Influence of interleukin gene polymorphisms on development of acute pancreatitis: a systematic review and meta-analysis. Mol Biol Rep. 2013 Oct;40(10):5931-41.

22 Bishu S, Koutroumpakis E, Mounzer R, Stello K, Pollock N, Evans A, et al. The -251 A/T Polymorphism in the IL8 Promoter is a Risk Factor for Acute Pancreatitis. Pancreas. 2018 Jan;47(1):87-91.

23 Teich N, Bokemeyer B, Mohl W, Walldorf J, Bruns T, Schmidt C, et al.; German IBD Study Group. Blood group B is associated with azathioprine-induced acute pancreatitis in patients with IBD. Gut. 2017 Aug;66(8):1531-2.

24 Singh VK, Wu BU, Bollen TL, Repas K, Maurer R, Mortele KJ, et al. Early systemic inflammatory response syndrome is associated with severe acute pancreatitis. Clin Gastroenterol Hepatol. 2009 Nov;7(11):1247-51.

25 Crockett SD, Wani S, Gardner TB, FalckYtter Y, Barkun AN, Crockett S, et al.; American Gastroenterological Association Institute Clinical Guidelines Committee. American Gastroenterological Association Institute Guideline on Initial Management of Acute Pancreatitis. Gastroenterology. 2018 Mar; 154(4):1096-101.

26 Yeung YP, Lam BY, Yip AW. APACHE system is better than Ranson system in the prediction of severity of acute pancreatitis. Hepatobiliary Pancreat Dis Int. 2006 May;5(2): 294-9.

27 Gravante G, Garcea G, Ong SL, Metcalfe MS, Berry DP, Lloyd DM, et al. Prediction of mortality in acute pancreatitis: a systematic review of the published evidence. Pancreatology. 2009;9(5):601-14. 
28 Ranson JH, Rifkind KM, Roses DF, Fink SD, Eng K, Spencer FC. Prognostic signs and the role of operative management in acute pancreatitis. Surg Gynecol Obstet. 1974 Jul; 139(1):69-81.

29 Blamey SL, Imrie CW, O’Neill J, Gilmour WH, Carter DC. Prognostic factors in acute pancreatitis. Gut. 1984 Dec;25(12):1340-6.

30 London NJ, Neoptolemos JP, Lavelle J, Bailey I, James D. Contrast-enhanced abdominal computed tomography scanning and prediction of severity of acute pancreatitis: a prospective study. Br J Surg. 1989 Mar;76(3) 268-72.

31 Wu BU, Johannes RS, Sun X, Tabak Y, Conwell DL, Banks PA. The early prediction of mortality in acute pancreatitis: a large population-based study. Gut. 2008 Dec;57(12): 1698-703.

32 Papachristou GI, Muddana V, Yadav D, O'Connell M, Sanders MK, Slivka A, et al. Comparison of BISAP, Ranson's, APACHEII, and CTSI scores in predicting organ failure, complications, and mortality in acute pancreatitis. Am J Gastroenterol. 2010 Feb; 105(2):435-41; quiz 442.

33 Werner J, Hartwig W, Uhl W, Müller C, Büchler MW. Useful markers for predicting severity and monitoring progression of acute pancreatitis. Pancreatology. 2003;3(2):115-

34 Pongprasobchai S, Jianjaroonwong V, Charatcharoenwitthaya P, Komoltri C, Tanwandee T, Leelakusolvong S, et al. Erythrocyte sedimentation rate and $\mathrm{C}$-reactive protein for the prediction of severity of acute pancreatitis. Pancreas. 2010 Nov;39(8):1226-30.

35 Khanna AK, Meher S, Prakash S, Tiwary SK, Singh U, Srivastava A, et al. Comparison of Ranson, Glasgow, MOSS, SIRS, BISAP, APACHE-II, CTSI Scores, IL-6, CRP, and Procalcitonin in Predicting Severity, Organ Failure, Pancreatic Necrosis, and Mortality in Acute Pancreatitis. HPB Surg. 2013;2013: 367581.

36 Schepers NJ, Bakker OJ, Besselink MG, Bollen TL, Dijkgraaf MG, van Eijck CH, et al.; Dutch Pancreatitis Study Group. Early biliary decompression versus conservative treatment in acute biliary pancreatitis (APEC trial): study protocol for a randomized controlled trial. Trials. 2016 Jan;17(1):5

37 Büchler M, Malfertheiner P, Schoetensack C Uhl W, Scherbaum W, Beger HG. [Value of biochemical and imaging procedures for the diagnosis and prognosis of acute pancreatitis - results of a prospective clinical study]. Z Gastroenterol. 1986 Feb;24(2):100-9.

38 Cardoso FS, Ricardo LB, Oliveira AM, Canena JM, Horta DV, Papoila AL, et al. C-reactive protein prognostic accuracy in acute pancreatitis: timing of measurement and cutoff points. Eur J Gastroenterol Hepatol. 2013 Jul; 25(7):784-9.
39 Gan SI, Romagnuolo J. Admission hematocrit: a simple, useful and early predictor of severe pancreatitis. Dig Dis Sci. 2004 Nov-Dec; 49(11-12): 1946-52.

40 Brown A, Orav J, Banks PA. Hemoconcentration is an early marker for organ failure and necrotizing pancreatitis. Pancreas. 2000 May; 20(4):367-72.

41 Lankisch PG, Mahlke R, Blum T, Bruns A, Bruns D, Maisonneuve P, et al. Hemoconcentration: an early marker of severe and/or necrotizing pancreatitis? A critical appraisal. Am J Gastroenterol. 2001 Jul;96(7):2081-5.

42 Kylänpää-Bäck ML, Takala A, Kemppainen EA, Puolakkainen PA, Leppäniemi AK, Karonen SL, et al. Procalcitonin, soluble interleukin-2 receptor, and soluble E-selectin in predicting the severity of acute pancreatitis. Crit Care Med. 2001 Jan;29(1):63-9.

43 Purkayastha S, Chow A, Athanasiou T, Cambaroudis A, Panesar S, Kinross J, et al. Does serum procalcitonin have a role in evaluating the severity of acute pancreatitis? A question revisited. World J Surg. 2006 Sep;30(9):171321.

44 Wu BU, Johannes RS, Sun X, Conwell DL, Banks PA. Early changes in blood urea nitrogen predict mortality in acute pancreatitis. Gastroenterology. 2009 Jul;137(1):129-35.

45 Wu BU, Bakker OJ, Papachristou GI, Besselink MG, Repas K, van Santvoort HC, et al. Blood urea nitrogen in the early assessment of acute pancreatitis: an international validation study. Arch Intern Med. 2011 Apr;171(7): 669-76.

46 Schepers NJ; Dutch Pancreatitis Study Group. Early endoscopic retrograde cholangiography with biliary sphincterotomy or conservative treatment in predicted severe acute biliary pancreatitis (APEC): a multicenter randomized controlled trial. 2018. Available from: https://www.ueg.eu/education/document/early-endoscopic-retrograde-cholangiography-with-biliary-sphincterotomy-or-conservative-treatment-in-predicted-severe-acute-biliary-pancreatitisapec-a-multicenter-randomized-controlledtrial/183992/.

47 de-Madaria E, Banks PA, Moya-Hoyo N, Wu BU, Rey-Riveiro M, Acevedo-Piedra NG, et al. Early factors associated with fluid sequestration and outcomes of patients with acute pancreatitis. Clin Gastroenterol Hepatol. 2014 Jun;12(6):997-1002.

48 Brown A, Baillargeon JD, Hughes MD, Banks PA. Can fluid resuscitation prevent pancreatic necrosis in severe acute pancreatitis? Pancreatology. 2002;2(2):104-7.
49 Wall I, Badalov N, Baradarian R, Iswara K, Li JJ, Tenner S. Decreased mortality in acute pancreatitis related to early aggressive hydration. Pancreas. 2011 May;40(4):547-50.

50 Mao EQ, Tang YQ, Fei J, Qin S, Wu J, Li L, et al. Fluid therapy for severe acute pancreatitis in acute response stage. Chin Med J (Engl). 2009 Jan;122(2):169-73.

51 Mao EQ, Fei J, Peng YB, Huang J, Tang YQ, Zhang SD. Rapid hemodilution is associated with increased sepsis and mortality among patients with severe acute pancreatitis. Chin Med J (Engl). 2010 Jul;123(13):1639-44.

52 Holodinsky JK, Roberts DJ, Ball CG, Blaser AR, Starkopf J, Zygun DA, et al. Risk factors for intra-abdominal hypertension and abdominal compartment syndrome among adult intensive care unit patients: a systematic review and meta-analysis. Crit Care. 2013 Oct;17(5):R249.

53 Wu BU, Hwang JQ, Gardner TH, Repas K, Delee R, Yu S, et al. Lactated Ringer's solution reduces systemic inflammation compared with saline in patients with acute pancreatitis. Clin Gastroenterol Hepatol. 2011 Aug;9(8): 710-717.e1.

54 Peake SL, Delaney A, Bailey M, Bellomo R, Cameron PA, Cooper DJ, et al.; ANZICS Clinical Trials Group. Goal-directed resuscitation for patients with early septic shock. N Engl J Med. 2014 Oct;371(16):1496-506.

55 Zhao G, Zhang JG, Wu HS, Tao J, Qin Q, Deng SC, et al. Effects of different resuscitation fluid on severe acute pancreatitis. World J Gastroenterol. 2013 Apr;19(13): 2044-52.

56 Windsor AC, Kanwar S, Li AG, Barnes E, Guthrie JA, Spark JI, et al. Compared with parenteral nutrition, enteral feeding attenuates the acute phase response and improves disease severity in acute pancreatitis. Gut. 1998 Mar;42(3):431-5.

57 Lankisch PG, Apte M, Banks PA. Acute pancreatitis. Lancet. 2015 Jul;386(9988):85-96.

58 Bakker OJ, van Brunschot S, van Santvoort HC, Besselink MG, Bollen TL, Boermeester MA, et al.; Dutch Pancreatitis Study Group. Early versus on-demand nasoenteric tube feeding in acute pancreatitis. N Engl J Med. 2014 Nov;371(21):1983-93.

59 Gülen B, Dur A, Serinken M, Karcıoğlu Ö, Sönmez E. Pain treatment in patients with acute pancreatitis: A randomized controlled trial. Turk J Gastroenterol. 2016 Mar;27(2): 192-6.

60 Blamey SL, Finlay IG, Carter DC, Imrie CW. Analgesia in acute pancreatitis: comparison of buprenorphine and pethidine. Br Med J (Clin Res Ed). 1984 May;288(6429):1494-5.

61 Suda KJ, Hicks LA, Roberts RM, Hunkler RJ, Danziger LH. A national evaluation of antibiotic expenditures by healthcare setting in the United States, 2009. J Antimicrob Chemother. 2013 Mar;68(3):715-8. 